\title{
Organ and prenatal toxicity of nonsteroidal anti-inflammatory drugs
}

\author{
Katarzyna Dyndor ${ }^{1}$, Wojciech Dworzanski ${ }^{1}$ MaŁgorzata Pliszczynska-Steuden $^{1}$, \\ Monika Cendrowska-Pinkosz ${ }^{1}$, Tomasz Chroscicki ${ }^{1}$, Przemyslaw Dyndor ${ }^{2}$, \\ Anna Dworzanska ${ }^{1}$, Ewa PiaseK ${ }^{1}$, Piotr Piech ${ }^{1}$, Marcin Ruchala ${ }^{1}$, \\ Katarzyna Golec ${ }^{1}$, Teresa Hermanowicz-Dryka ${ }^{1 *}$
}

${ }^{1}$ Human Anatomy Department, Medical University of Lublin, Jaczewskiego 4, 20-090 Lublin, Poland

${ }^{2}$ Chair and Department of Rehabilitation and Orthopaedics, Medical University of Lublin, Jaczewskiego 8, 20-950 Lublin, Poland

\begin{tabular}{|c|c|}
\hline ARTICLE INFO & ABSTRACT \\
\hline $\begin{array}{l}\text { Received } 09 \text { July } 2015 \\
\text { Accepted } 26 \text { August } 2015\end{array}$ & $\begin{array}{l}\text { Non-selective cyclooxygenase (COX) inhibitors, commonly referred to as nonsteroidal } \\
\text { anti-inflammatory drugs (NSAIDs), are among the most taken pharmaceuticals. In }\end{array}$ \\
\hline $\begin{array}{l}\text { Keywords: } \\
\text { NSAIDs, } \\
\text { organ toxicity, } \\
\text { developmental toxicity, } \\
\text { reproductive toxicity. }\end{array}$ & $\begin{array}{l}\text { adults, they can have a series of side effects, including especially gastroenterotoxicity, } \\
\text { hepatotoxicity, nephrotoxicity, chondrotoxicity, and neurotoxicity, and they can induce } \\
\text { allergic reactions. Any exacerbation of symptoms depends on the chemical structure of } \\
\text { the drug, its dosage and duration of exposure, individual sensitivity, comorbidities and } \\
\text { the degree of inhibition of basic COX isoenzymes - the constitutive (COX-2) and induced } \\
\text { (COX-1) expressions. However, data on prenatal toxicity are inconsistent. Classic non- } \\
\text { selective COX inhibitors do not result in an increase in the risk of developing significant } \\
\text { congenital defects; however, if used in the late-pregnancy period, they can have an } \\
\text { adverse effect on the foetus, by inducing the premature closure of the ductus arteriosus } \\
\text { and by producing a tocolytic effect. Individual reports also indicate the increased risk of } \\
\text { developing heart and anterior abdominal wall defects, as well as hypospadias. }\end{array}$ \\
\hline
\end{tabular}

\section{INTRODUCTION}

Non-selective cyclooxygenase (COX) inhibitors, commonly referred to as nonsteroidal anti-inflammatory drugs (NSAID's), are among the most frequently taken pharmaceuticals by pregnant women and the remaining members of the populace. Their popularity is facilitated by accessibility, as they are available for purchase in pharmacies, as well as in kiosks, grocery stores and petrol stations. The drugs in question are used so often because they have antiplatelet, analgesic, antipyretic, anti-inflammatory and tocolytic effects $[13,15,40]$. In contrast to the well-researched organ toxicity in adults, the adverse effects of COX inhibitors in pregnancy have not yet been fully explained [4,34]. Most of the discussed xenobiotics can cross the placental barrier and reach therapeutic or sub-therapeutic concentrations in the blood of the foetus, as in the serum of the mother $[5,8]$.

\begin{tabular}{l} 
^Corresponding author \\
e-mail: wojciech686@wp.pl \\
tel.: +48662146283 \\
\hline
\end{tabular}

\section{ORGAN TOXICITY}

It is estimated that 13 out of 1000 patients that had been treated with non-selective NSAIDs for a year due to rheumatoid arthritis experience severe digestive system complications [37]. Moreover, the most common reason stated for stopping NSAID usage is dyspepsia, which is observed in ca. $10-20 \%$ of patients. Rarer cases involve serious digestive system damage in the form of mucosal erosion and ulceration, and also upper gastrointestinal tract perforations and bleeding. The mortality of patients treated with NSAIDs, resulting from upper gastrointestinal tract complications, is estimated at $0.22 \%$, which, taking into account the sheer number of this patient group, poses a significant clinical problem. Gastrointestinal mucosal injuries are primarily conditioned by an affinity for COX-1 and the direct impact on the gastric mucosa, which in turn depends on the chemical structure of the drug. Such injuries are most often observed in patients with Helicobacter pylori infection, as well as peptic ulcer disease, and in the elderly.

As anticipated, selective COX-2 inhibitors are characterised by much better gastrointestinal tolerance. This has been corroborated by numerous clinical trials, including 
CLASS and VIGOR trials, which aimed at comparing the side effects of coxibes and non-selective NSDAIDs. The VIGOR (Vioxx Gastrointestinal Outcomes Research) trial demonstrated that bleeding or ulcer perforations in the upper gastrointestinal tract in the case of Naproxen $500 \mathrm{mg}$ administered bi-daily, appeared twice as often as in the case of rofecoxib $50 \mathrm{mg}$, in patients with rheumatoid arthritis [3]. In the CLASS (Celecoxib Long-term Arthritis Safety Study) trial, patients administered celecoxib $400 \mathrm{mg}$ twice a day, displayed better tolerance than did patients administered diclofenac and ibuprofen in anti-inflammatory doses [37]. The latter (diclofenac and ibuprofen) caused a significant increase in the number of ulcers in the upper gastrointestinal tract when compared with patients treated with celecoxib. What is more, in the case of the simultaneous administration of anticoagulant doses of acetylsalicylic acid, an increase in the prevalence of gastric and duodenal mucosa injuries was observed in patients treated with celecoxib.

While COX-1 is a dominant isoenzyme in the gastrointestinal tract, in both animals and humans, researchers could observe the presence of the constitutive expression of COX-2 in the gastric mucosa, which suggests its physiological function [29]. An elevated level of COX-2 was revealed in the marginal tissue of peptic ulcers and in gastric mucosa damaged by perfusion disorders and hypoxia. It is considered that $\mathrm{COX}$-2-derivative prostaglandins participate in the process of damaged-tissue repair by stimulating the creation of granulation tissue and angiogenesis. Coxibes should therefore be administered to patients suffering from active peptic ulcer disease with extreme caution, which even then, however, might be inadvisable.

Both COX-1 and COX-2 condition the correct renal function. Constitutively secreted $\mathrm{COX}-2$ was located in renal vessels, the interstitial cells of the renal medulla and the macula densa, while the highest expression of COX-1 was found in the nephron connecting tubules and the loop of Henle [24,28]. As expected, both selective and non-selective COX inhibitors can impair renal flow and glomerular filtration, as well as sodium and potassium excretion, which leads to swelling, pressure increase and hyperkalemia. This was confirmed by numerous studies [16,18]. Moreover, it was demonstrated that selective COX-2 inhibitors inhibit renin secretion in the macula densa, stimulated by a decrease in sodium concentration. In addition, it was reported that the average pressure increase in NSAID therapy amounts to 3-5 $\mathrm{mmHg}$ [23]. Also, there were reports of acute interstitial nephritis and membranous glomerulopathy following celecoxib treatment, and of nephrotoxicity, which was previously attributed to non-selective NSAIDs alone [28].

One of the commonly known side effects of using nonselective NSAIDs is the increased risk of bleeding. This situation comes about depending on the inhibition of platelet activity by COX-1. Selective COX-2 inhibitors do not display antithrombotic action, but can intensify blood coagulation by inhibiting the synthesis of prostacyclins in the endothelium $[18,27]$. This, however, was not explicitly confirmed in clinical trials [23]. Furthermore, it was demonstrated that coxibes nullify the anticoagulant action of small doses of aspirin. On the other hand, reports of an increased risk of myocardial infarction during treatment with coxibes are yet to be confirmed [16]. Animal tests did, however, demonstrate increased sensitivity of cardiac muscle cells to prostacyclin-deficiency-dependent ischaemia. In VIGOR it was observed that cardiac infarctions occurred significantly more frequently in patients treated with rofecoxib than in patients taking naproxen [3]. These results were not considered credible due to the low number of cardiovascular incidents among the researched patients.

Many adverse reactions can occur as a result of an allergic reaction. NSAIDs, alongside sulphonamide and penicillin, are among the most allergenic drug groups [26]. The most common complications include skin lesions and angio-oedema. Cases of an anaphylactic shock and StevensJohnson syndrome are rarer. Selective COX-2 inhibitors are not free of such complications. Allergic reactions to coxibes in patients allergic to non-selective NSAIDs have been reported [32]. In contrast to old-generation NSAIDs, the impact of selective COX-2 inhibitors on the bone marrow remains unknown. Impaired immunological response might be one of the causes of bronchospasm or aspirin-induced asthma during the use of old-generation COX inhibitors. Szczeklik et al. indicate that a COX-2 block does not result in the creation of mediators responsible for bronchospasm attacks; thus selective COX-2 inhibitors are safe for patients with NSAID-induced asthma [38].

Another side effect, independent of COX suppression, is hepatoxicity. Most described cases were clinically mild and manifested in elevated aminotransferase levels [43]. Holestatic presentation is relatively rare. Non-selective NSAIDs and coxibes should be used with the utmost care in the case of patients with liver failure.

The prolonged use of COX inhibitors can have a toxic effect on joint cartilage. It was demonstrated in clinical studies that some NSAIDs, such as indomethacin, can exacerbate the progression of degenerative lesions in the joint cartilage in the course of osteoarthritis [26]. This, most probably, is caused by the inhibited synthesis of glycosaminoglycans and collagen in the cartilage by some NSAIDs. Based on experimental work, COX inhibitors were placed within into three groups, depending on their impact on cartilage metabolism [21]:

1. COX inhibitors stimulating the synthesis of the cartilage matrix, such as tolmetin.

2. COX inhibitors with no impact on the synthesis of the cartilage matrix, such as piroxicam and acetylsalicylic acid.

3. COX inhibitors inhibiting the synthesis of the extracellular matrix, such as ibuprofen, naproxen and nimesulide.

\section{DEVELOPMENTAL AND REPRODUCTIVE TOXICITY}

Epidemiological studies indicate that prenatal exposure to certain drugs is responsible for ca. $1 \%$ of all congenital defects [35]. Most xenobiotics can cross the inefficient placental barrier and enter the foetal circulation $[4,17,19$, $30,33,40,42]$. The group of COX inhibitors in question does not display clear embryotoxicity or teratogenicity. So far no relevant data supporting the complete safety of the mother and the child/foetus have been found. Acetylsalicylic acid displays the highest documented development toxicity. 
However, Sibali et al. [36] revealed that small doses of this drug should not be contraindicated. On the other hand, the prolonged use of significant doses of this pharmaceutical substantially increases the risk of miscarriage, intrauterine growth restriction and the closure of the ductus arteriosus, which is the most common complication. Indomethacin does not impact on the ductus arteriosus diameter until the $27^{\text {th }}$ week of pregnancy in humans. However, an observable effect was demonstrated at $27-30^{\text {th }}$ and $31-34^{\text {th }}$ weeks of pregnancy, when 43 and $61 \%$ stenoses were respectively indicated. A direct consequence of the stenosis or closure of the ductus arteriosus is pulmonary hypertension in newborns and infants [1].

Intrauterine exposure of the foetus to xenobiotics can trigger the abnormal development of the child. Due to the mother taking of such items, an increased risk of congenital defects was observed, including heart defects. This was, however, only observed for a group of COX inhibitors, and not for a specific substance. It is worth highlighting that in the offspring of women exposed to xenobiotics, researchers observed an increased frequency of ventricular septal defects alone [5-8]. On the other hand, Torfs et al. [39] have shown not only the increased prevalence of heart defects, but also of cleft lip and/or palate in the offspring of women who took COX inhibitors in pregnancy. It is important to note that Werler et al. [41] demonstrated an increased prevalence of premature birth and giving birth to children with low birth weight in such situations.

Burdan et al. [10,11] observed that intrauterine exposure of rat foetuses to $\mathrm{COX}$ inhibitors increased the prevalence of anterior abdominal wall defects. Cook et al. [20] presented similar findings. However, these were restricted to non-selective COX inhibitors. The authors described the dose-dependent intrauterine growth restriction of laboratory animal foetuses $[5,7,8,10,22]$. It is also important to note that in the case of COX-2 inhibitors, the described complication appeared after the administration of high doses, exceeding the threshold of selectivity $[9,12]$.

Another epidemiologically confirmed complication of using COX inhibitors (as a group, and not a specific preparation) is the increased risk of miscarriage [31]. Salhab et al. [32] pointed out the appearance of ovulation disorders during the administration of COX inhibitors. However, no contraceptive action of the drug group in question was demonstrated.

It is also worth reminding that selective COX inhibitors administered in high doses disturb the wellbeing of the expectant mother, and have an adverse effect on the development of the foetus. These observations corroborate the increased prevalence of external developmental variants and developmental variants of the skeleton, which, according to experimental data, can normalise over time [4,2,24]. Nevertheless, the role of disorders in the function and morphology of the placenta in their etiopathogenesis remains unknown. Briggs et al. [20] indicate that xenobiotics can easily cross the placental barrier which separates the mother's circulatory system from the foetal circulation.

\section{CONCLUSIONS}

1. Non-selective COX-2 inhibitors have lower organ tolerability when compared with selective COX-2 inhibitors.

2. Non-selective and selective COX inhibitors can prevent or retard ovulation, but the degree of ovulation inhibition is unknown.

3. Non-selective COX inhibitors are not teratogenic and can be continued during the first and second trimester of pregnancy.

4. After gestational week 20, all NSAIDs (except aspirin at doses less than $100 \mathrm{mg} /$ day) can cause constriction of the ductus arteriosus and can impair foetal renal function.

5. All NSAIDs, except low-doses of aspirin (less than $325 \mathrm{mg}$ /day), should be withdrawn at gestational week 32.

6. NSAIDs intake should be limited or even prohibited around conception due to the revealed high association between those medications and miscarriage.

7. COX inhibitors, like other drugs, should be used at the lowest therapeutical dose, to limit maternal toxicity.

\section{REFERENCES}

1. Alano M.A. et al.: Analysis of nonsteroidal antiinflammatory drugs in meconium and its relation to persistent pulmonary hypertension of the newborn. Pediatrics, 107, 519-523, 2001.

2. Beck S.L.: Prenatal and postnatal assessment of maneb-exposed CD-1 mice. Reprod. Toxicol., 4, 83-290, 1990.

3. Bombardier C. et al.: VIGOR Study Group.Comparison of upper gastrointestinal toxicity of rofecoxib and naproxen in patients with rheumatoid arthritis. VIGOR Study Group. N Engl J Med., 343, 15201528, 2000.

4. Briggs GG. et al.: Drugs in pregnancy and lactation. A reference guide to fetal and neonatal risk. Lippincott Williams \& Wilkins, Philadelphia, 2005.

5. Burdan F. et al.: Celosomy is associated with prenatal exposure to cyclo-oxygenase inhibitors. Pharmacol. Res., 53, 287-292, 2006.

6. Burdan F. et al.: Congenital ventricular septal defects and prenatal exposure to cyclooxygenase inhibitors. Braz. J. Med. Biol. Res., 39, 925-934, 2006.

7. Burdan F. et al.: Immuno-expression of the constitutive and inducible cyclo-oxygenase isoforms in maternal and fetal rat lungs. Ann. Univ. Mariae Curie Sklodowska Med. [Sectio D], 61, 330-334, 2006.

8. Burdan F. et al.: Localization of cyclo-oxygenase isoforms in maternal and offspring kidney during pregnancy and lactation. Ann. Univ. Mariae Curie Sklodowska Med. [Sectio D], 61, 326-329, 2006.

9. Burdan F. et al.: Prenatal effects of DuP-697 - the irreversible, highly selective cyclo-oxygenase-2 inhibitor. Reprod. Toxicol., 17, 413-419, 2003.

10. Burdan F. et al.: Skeletal developmental effects of selective and nonselective cyclo-oxygenase-2 inhibitors administered through organogenesis and fetogenesis in Wistar CRL.(WI)WUBR rats. Toxicology, 216, 204-223, 2005.

11. Burdan F. et al.: Prenatal tolerability of acetaminophen and other over-the-counter non-selective cyclo-oxygenase inhibitors. Pharmacol. Res., 64, 521-527, 2012.

12. Burdan F.: Comparison of developmental toxicity of selective and non-selective cyclo-oxygenase-2 inhibitors in CRL.(WI)WUBR Wistar rats - DFU and piroxicam study. Toxicology, 211, 12-25, 2005.

13. Burdan F.: Developmental effects of propyphenazone in analgesic and antipyretic combination with caffeine or paracetamol. Hum. Exp. Toxicol., 23, 235-244, 2004.

14. Burdan F.: Developmental toxicity evaluation of ibuprofen and tolmetin administered in triple daily doses to Wistar CRL.(WI) WUBR rats. Birth Defects Res Part B Dev Reprod. Toxicol., 71, 321-330, 2004. 
15. Burdan F.: Intrauterine growth retardation and lack of teratogenic effects of prenatal exposure to the combination of paracetamol and caffeine in Wistar rats. Reprod. Toxicol., 17, 51-58, 2003.

16. Cannon C.P. et al.: Cardiovascular outcomes with etoricoxib and diclofenac in patients with osteoarthritis and rheumatoid arthritis, in the Multinational Etoricoxib and Diclofenac Arthritis Long-term (MEDAL) programme: a randomized comparison. Lancet, 368, 17711781, 2006.

17. Carter A.M.: Evolution of factors affecting placental oxygen transfer. Placenta, 2009, 19-25.

18. Chaiamnuay S. et al.: Risks versus benefits of cyclo-oxygenase-2selective nonsteroidal anti-inflammatory drugs. Am. J. of HealthSystem Pharm., 19, 1848-1851, 2006.

19. Chernoff N. et al.: Significance of supernumerary ribs in rodent developmental toxicity studies: postnatal persistence in rats and mice. Fundam. Appl. Toxicol., 17, 448-453, 1991.

20. Cook J.C. et. al.: Analysis of the nonsteroidal anti-inflammatory drug literature for potential developmental toxicity in rats and rabbits. Birth. Defects Res. B. Dev. Reprod. Toxicol., 68, 5-26, 2003.

21. Dingle J.T. The effects of NSAID on the matrix human articular cartilages. Z. Rheumatol., 58, 125-129, 1999.

22. Fritz H.: Prenatal ossification in rabbits as indicative of fetal maturity. Teratology. 11. 313-319, 1975.

23. Hippisley-Cox J., Coupland C.: Risk of myocardial infarction in patients taking cyclo-oxygenase-2 inhibitors or conventional nonsteroidal anti-inflammatory drugs: population based nested casecontrol analysis. Br. Med. J., 330, 1366, 2005.

24. Khan K.N. et al.: Expression of cyclo-oxygenase-2 in the macula densa of human kidney in hypertension, congestive heart failure and nephropathy. Ren Fail., 23, 321-330, 2001.

25. Khera K.S.: Common fetal aberrations and their teratologic significance: a review. Fundam. Appl. Toxicol., 1, 13-18, 1981.

26. Mandell B.F.: General tolerability and use of nonsteroidal antiinfammatory drugs. Am. J. Med., 107, 72-76, 1999.

27. Mardini I.A. Fitzgerald G.A.: Selective inhibitors of cyclooxygenase-2. Am. Soci. Pharm. Exp. Therap., 1, 30-43, 2001.

28. Markowitz G.S. et al.: Membranous glomerulopathy and acute interstitial nephritis fallowing treatment with celecoxib. Clin. Nephrol., 59, 137-142, 2003.
29. Radi Z.A., Khan N.K.: Effects of cyclo-oxygenase inhibition on the gastrointestinal tract. Exp. Toxicol. Pathol., 58, 163-173, 2006.

30. Østensen M., et al. Pregnancy and reproduction in autoimmune rheumatic diseases. Rheumatology (Oxford)., 50, 657-664, 2011

31. alhab A.S. et al.: Meloxicam inhibits rabbit ovulation. Contraception. 63, 329-333, 2001.

32. Sanchez-Borges M.: Tolerability to new COX-2 inhibitors in NSAIDsensitive patients with cutaneous reactions. Ann Allergy Asthma Immunol., 87, 201-204, 2001.

33. angha R.K. et al.: Immunohistochemical localization, messenger ribonucleic acid abundance, and activity of 15-hydroxyprostaglandin dehydrogenase in placenta and fetal membranes during term and preterm labor. J. Clin. Endocrinol. Metab., 78, 982-989, 1994.

34. Scheaffer C. et al.: Drugs during pregnancy and lactation. 2 ed. (2007). Academic Press; Londyn.

35. Scialli A.R. et al.: Communicating risks during pregnancy: a workshop on the use of data from animal developmental toxicity studies in pregnancy labels for drugs. Birth Defects Res. A. Clin. Mol. Teratol., 70, 7-12, 2004

36. Sibal B.M., et al.: Low-dose aspirin in pregnancy. Obstet. Gynecol., 74, 551-557, 1989.

37. Silverstein F.E. et all.: Gastrointestinal toxicity with celecoxib vs nonsteroidal anti-inflammatory drugs for osteoarthritis and rheumatoid arthritis: the CLASS study: A randomized controlled trial. Celecoxib Long-term Arthritis Safety Study. JAMA, 284, 12471255, 2000.

38. Szczeklik A. et al.: Safety of a specific COX-2 inhibitor in aspirin induced asthma. Clin. Exp. Allergy., 31, 219-225, 2001.

39. Torfs C.P. et al.: Maternal medications and environmental exposures as risk factors for gastroschisis. Teratology, 54, 84-92, 1996.

40. Vermillion S.T. et al.: The effect of indomethacin tocolysis on fetal ductus arteriosus constriction with advancing gestational age. Am. J. Obstet. Gynecol., 177, 256-261, 1997.

41. Werler M.M., et al.: Use of over-the-counter medications during pregnancy. Am. J. Obstet. Gynecol., 193, 771-777, 2005.

42. Yasuda S. et al.: Placental folate transport during pregnancy. Biosci. Biotechnol. Biochem., 72, 2277-2284, 2008.

43. Zimmerman H.J. Ishak K.G. General aspects of drug induced liver disease. Gastroenterol. Clin. North Am., 24, 793-757, 1995. 